\title{
Electrospun Poly(L,D-lactide) Scaffolds Support the Growth of Human Embryonic Stem Cell-derived Neuronal Cells
}

\author{
Laura Ylä-Outinen ${ }^{1}$, Christine Mariani ${ }^{2}$, Heli Skottman ${ }^{1}$, Riitta Suuronen ${ }^{1,3,4}$, Ali Harlin ${ }^{2}$ and \\ Susanna Narkilahti ${ }^{*}, 1$
}

${ }^{I}$ Regea-Institute for Regenerative Medicine, University of Tampere and Tampere University Hospital, Tampere, Finland

${ }^{2}$ Department of Material Science, Tampere University of Technology, Tampere, Finland

${ }^{3}$ Department of Eye, Ear, and Oral Diseases, Tampere University Hospital, Tampere Finland

${ }^{4}$ Department of Biomedical Engineering, Tampere University of Technology, Tampere Finland

\begin{abstract}
Stem cell-derived cells, especially neural derivatives, are currently attracting considerable attention as a future source of clinical transplantations for the treatment of various neurodegenerative diseases and insults. Human embryonic stem cells (hESC) offer an unlimited source for the production of neural cells. Transplantation of these cells, however, does not necessarily result in optimal cell graft survival, and therefore functional improvement by in vitro engineering of the cell grafts is necessary. Here, we evaluated the effects of a clinically relevant substrate, poly(L,D-lactide) (PLDLA), as a growth matrix for hESC-derived neurons on cell viability, growth, and maturation. The results were analyzed using a cell viability test, immunocytochemistry, neuron and neurite outgrowth counts, and scanning electron microscopy. In vitro culturing of cells on PLDLA scaffolds induced the differentiation, maturation, and growth of neurites comparable to cells grown on a laminin surface during 7 days follow up. These results suggest that PLDLA is a potential substrate for the preparation of neural tissue-engineered products.
\end{abstract}

Keywords: Differentiation, Nerve tissue engineering, Neural cell, Neurite outgrowth, Poly(lactide), Scaffold, Stem cell.

\section{INTRODUCTION}

Stem cells, especially embryonic stem cells, have an unlimited capacity to proliferate and differentiate into any kind of human body cell type. These unique properties make stem cells a potentially valuable source of living material for tissue engineering, especially for tissues with low selfrenewable capacity, like nerve tissue [1]. Regenerative treatments for neurologic deficits are thus currently focused on stem/neural cell transplantations [2]. Human and animal studies indicate that transplantations have some beneficial functional effects, but the survival, migration, maturation, and integration of transplanted cells needs to be enhanced [2, 3]. Thus, more sophisticated approaches toward combining cells and supporting biomaterials, mimicking the extracellular matrix, may lead to tissue engineering applications for both the central and peripheral nervous system [4].

Both natural and synthetic biomaterials have been tested as matrices for neural cells [1,5-10]. To create functional cell grafts, the supporting matrix should have a structure that enhances cell survival, proliferation, maturation, and targeted growth, which sets up specific requirements for the material. For example, the selected material should enable cell attachment and targeted neurite outgrowth [11] which may be further facilitated by incorporated biomolecules [12].

*Address correspondence to this author at the Regea-Institute for Regenerative Medicine, University of Tampere, Biokatu 12, 33520 Tampere, Finland; Tel: + 358 407085113; Fax: + 35833551 8498; E-mail: susanna.narkilahti@regea.fi
Further, for clinical relevance, the material(s) should be tested particularly with human-derived neural cells for tissue engineering purposes.

Polylactide-based products are already widely used in clinics. Polylactides can be easily processed into different forms, such as nanofibers via phase separation, template synthesis, drawing, or electrospinning [9, 13, 14]. Poly(Llactide) nano/micro fibrous scaffolds produced by electrospinning have been successfully used for culturing neural stem cells derived from neonatal mouse brain [10]. These studies suggest that the material selected to support the neurite outgrowth should contain fibers that are less than $5 \mu \mathrm{m}$ in diameter $[10,11]$. In particular, the electrospinning technique enables easy and efficient production of nanoscale fibers $[3,13]$.

Electrospinning is a technique in which an electrostatic field is used to prepare nano-scale fibres from polymer solutions and melts. The principle of the electrospinning method is quite simple - the electrostatic field stretches the polymer solution into jets while the solvent evaporates away. The fibres solidify while collected onto metal collectors of different shapes. By varying the shape of the collector, aligned or randomly oriented fibres, 2D or 3D structures, or certain shaped scaffolds can be processed $[9,15]$.

Here, we cultured hESC-derived neural cells on electrospun 3D poly(L,D-lactide) (PLDLA) scaffolds for 7 days. Cell viability, attachment, neuronal phenotype, and neurite outgrowth were evaluated. The results indicated that thick 3D PLDLA scaffolds supported neuronal cells as well as the typical culturing matrix laminin. 


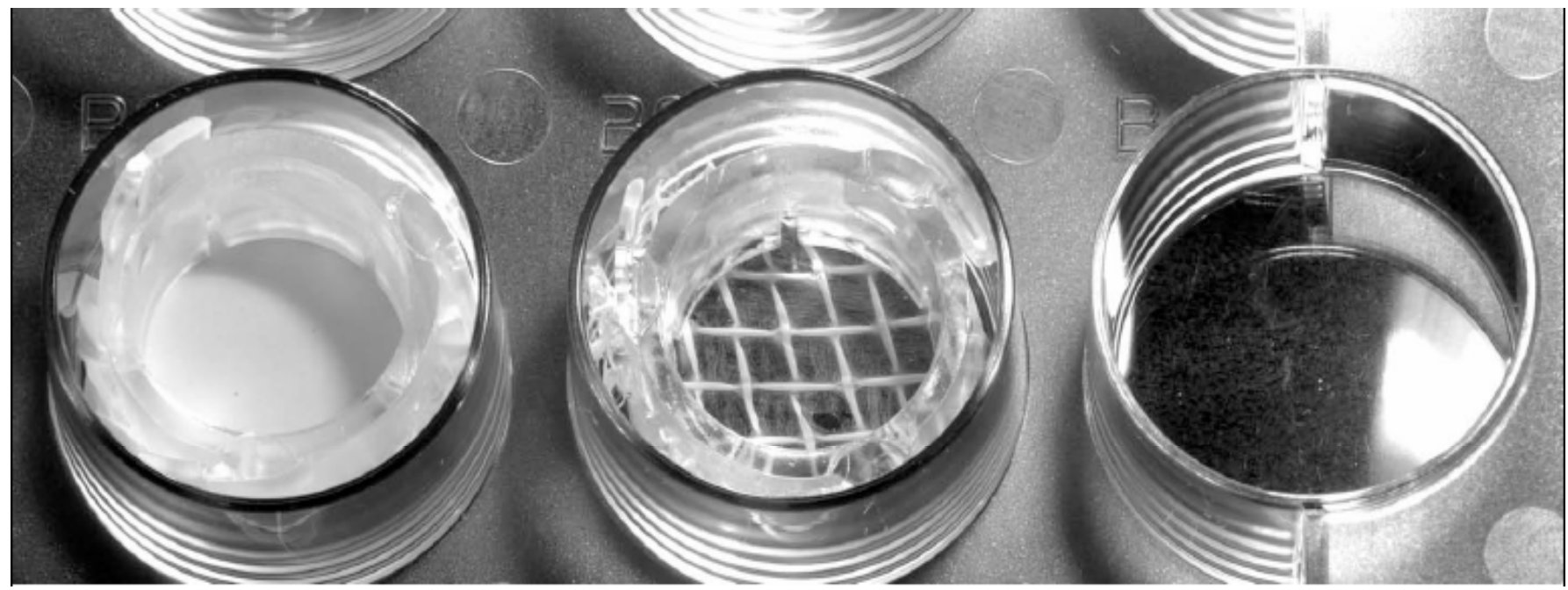

Fig. (1). Experimental design. Two types of PLDLA scaffolds were anchored on the bottom of 12-well plates with CellCrown inserts. Left: thick PLDLA scaffold; Middle: thin PLDLA scaffold; Right: laminin-coated well bottom. Cells were seeded into wells after a 2-day preincubation period in cell culture medium.

\section{MATERIALS AND METHODS}

\section{PLDLA}

Co-polymer PLDLA containing two chiral lactide forms: 4\% D-lactide and 96\% L-lactide was purchased from Purac Biochem (The Netherlands). The viscosity of the polymer pellets was $2.18 \mathrm{dl} / \mathrm{g}$ according the manufacturer's data sheet. The molecular weight of the polymer was 93,732 $\mathrm{g} / \mathrm{mol}$, determined by gel permeation chromatography [16].

\section{Fabrication and Preprocessing of Scaffolds}

The PLDLA was dissolved in 1,1,1,3,3,3-hexafluoroisopropanol at room temperature to form a $5 \%$ polymer solution. The resulting polymer solution was electrospun in a $2-\mathrm{kV} / \mathrm{cm}$ electric field and the distance between the spinning needle and collector was $15 \mathrm{~cm}$. The spinning process was performed as described previously [15].

Two types of mesh were processed. The first structure (thin 3D scaffold) was fabricated on a metal grid (wire distance approximately $2.5 \mathrm{~mm}$ ) so that the electrospun fibres formed a thick mesh on top of the metal wires, whereas thinner mesh were formed between the wires. The structure was highly oriented along the grid wires.

The second structure (thick 3D scaffold) was fabricated on a flat copper dish (smooth collector) resulting in a freely formed randomly-oriented 3D structure. Both types of mesh were processed to samples of $3.5 \mathrm{~cm}$ in diameter and sterilized with gamma radiation (26-30 kGy). The formed structures are shown in Fig. (1).

\section{Pre-Incubation of PLDLA Scaffolds}

PLDLA scaffolds were placed on the bottom of 12 culture wells (Nunc, Denmark) with CellCrown inserts (Scaffdex, Finland). Scaffolds were pre-incubated with cell culture medium (composition described below) at $+37^{\circ} \mathrm{C}$ for 2 days. The medium $\mathrm{pH}$ was measured repeatedly during and after pre-incubation with Duotest pH-paper (MachereyNagel, Germany).

\section{Cell Culture and Seeding}

The hESCs (HS360 and HS362) were cultured on postnatal human foreskin fibroblasts as previously described [17]. Regea, Institute for Regenerative Medicine, University of Tampere, Finland has the approval of the Ethical Committee of Pirkanmaa Hospital District to culture hESC lines derived at Karolinska Institute (1426/32/300/05). The hESC colonies were cut into small pieces and placed in neural differentiation medium containing Dulbecco's Modified Eagle's Medium/F12 (Gibco, Invitrogen, Finland) and Neurobasal medium (Gibco) 1:1, supplemented with $2 \mathrm{mM}$ GlutaMax (Gibco, USA), 1× B27 (Gibco), 1× N2 (Gibco), $20 \mathrm{ng} / \mathrm{ml}$ fibroblast growth factor (R\&D Systems, Minneapolis, MN), and penicillin/streptomycin $(25 \mathrm{U} / \mathrm{ml}$, Cambrex, Belgium). HESCs formed neurospheres in suspension culture as previously described [18]. The medium was changed 3 times per week and the spheres were mechanically dissected on a weekly basis. Neurospheres were cultured for 6 to 8 weeks prior to seeding onto the scaffolds at the state when they were fully differentiated into neural cells that further differentiate into neurons [19].

Cells were dissociated into a mixed suspension containing both single cells and cell clusters. There after, $\sim 100000$ single cells and 3 to 5 cell clusters were seeded onto PLDLA-scaffolds. In addition, cells were seeded onto laminin (10 $\mu \mathrm{g} / \mathrm{ml}$, Sigma-Aldrich, Finland), which served as a positive growth matrix control. Cells seeded on non-treated polystyrene wells were used as a negative growth matrix control.

\section{PLDLA Scaffolds Functionalized with Laminin}

Additional PLDLA scaffolds were treated with 10, 5, 1, and $0.1 \mu \mathrm{g} / \mathrm{ml}$ laminin prior to cell seeding. Briefly, $500 \mu 1$ of each laminin solution was added to pre-incubated scaffolds and incubated for $2 \mathrm{~h}$ at $37^{\circ} \mathrm{C}$. For cell experiments, scaffolds were washed $3 \times$ with phosphate buffered saline (PBS) prior to medium adding and cell seeding. Cells were allowed to grow onto scaffolds for 7 days prior to analysis. To evaluate the incorporation of laminin by physical 
absorption onto PLDLA fibers, FITC labeling kit (Calbiochem, Germany) was used. First, laminin coated PLDLA samples were rinsed carefully with carbonate buffer. Thereafter, FITC solution $(1 \mathrm{mg} / \mathrm{ml})$ was added and incubated 5 minutes with samples in room temperature. The unbound FITC was rinsed with PBS and samples were imaged with Olympus IX51 inverted microscope with fluorescence set up combined with Olympus DB71 digital camera (Olympus, Finland) with constant exposure time of $1400 \mathrm{~ms}$.

\section{Cell Viability and Neurite Outgrowth Studies}

During the 7 days of culturing on PLDLA-scaffolds, cell attachment and growth were evaluated with contrast-phase microscopy (Nikon, Finland).

\section{Live/Dead Assay}

After 7 days of culturing on the scaffolds or control wells, cells were stained using the Live/Dead Viability/Cytotoxicity Kit for mammalian cells (Molecular Probes/Invitrogen, Finland). Briefly, the kit stains live cells with the green fluorescence dye calcein-AM (emission at $488 \mathrm{~nm}$ ) and dead cells with the red fluorescence dye ethidium homodimer-1 (emission at $568 \mathrm{~nm}$ ). Cells were incubated with calcein-AM $(0.1 \mu \mathrm{M})$ and ethidium homodimer-1 $(0.5 \mu \mathrm{M})$ for 30 minutes and immediately imaged with fluorescence microscope system described above (Olympus). Three representative images $(\times 10$ objective) were obtained and $~ 100$ cells/group were counted.

\section{Immunocytochemical Characterization}

Cells were fixed with $4 \%$ paraformaldehyde (Fluka, Italy) and stained with neuronal markers. Briefly, cells were blocked with $10 \%$ normal donkey serum (NDS, Sigma), $0.1 \%$ Triton-X 100 (Sigma), and 1\% bovine serum albumin (BSA, Sigma) for $45 \mathrm{~min}$ at room temperature. The cells were then washed once with $1 \%$ NDS, $0.1 \%$ Triton-X, and $1 \%$ BSA. Primary antibodies; rabbit anti-microtubule associated protein (MAP-2, 1:800, Chemicon International, Millipore, Massachusetts, MA) or mouse anti-neurofilament 200 kD (NF-200, 1:600, Sigma), in 1\% NDS, 0.1\% Triton$\mathrm{X}$, and $1 \%$ BSA were incubated at $+4^{\circ} \mathrm{C}$ overnight. Cells were washed three times with $1 \%$ BSA and secondary antibodies, Alexa fluor 488 anti-rabbit (1:400, Molecular Probes) and Alexa fluor 488 anti-mouse IgG (1:400, Molecular Probes) in 1\% BSA were added for $1 \mathrm{~h}$ at room temperature. Finally, cells were washed three times with PBS and twice with phosphate buffer and mounted with Vectashield containing DAPI (4',6-diamidino-2phenylindole, Vector Laboratories, England), then imaged with the Olympus IX51 system.

\section{Scanning Electron Microscopy}

For scanning electron microscopy (SEM), scaffolds samples were fixed with $5 \%$ glutaraldehyde overnight at room temperature. Thereafter, samples were washed with PBS and post-fixed with $1 \%$ osmium tetroxide. Samples were then dried with a critical point dryer to preserve the cellular structures. Finally, samples were sputtered with gold and observed with a JEOL Scanning Electron Microscope JSM-5500 with PGT Prism 2000-Si(Li) EDS detector.

\section{Cell and Neurite Length Counting}

Neuronal cells and neurites were counted from immunofluorescence images. At least four $10 \times$ objective views were randomly captured from each sample (1 to 2 samples/group). A total of 417 to 986 cells/group were observed with nuclear staining (DAPI) and the portion of neuronal cells, that is, MAP-2 positive cells, was calculated. The number and length of neurites per neuron were then calculated from at least 70 neurons/group with Cell*software (Olympus).

\section{Statistics}

Statistical analyses were performed using SPSS v.11 software. Differences in neuronal growth and neurite lengths between different sample groups were analyzed using a nonparametric Kruskall Wallis test (> 2 groups) followed by Mann Whitney post hoc analysis. A p-value of less than 0.05 was considered statistically significant.

\section{RESULTS}

\section{Biocompatibility of PLDLA-Electrospun Scaffold}

The fabrication process was optimized so that the mesh was strong enough not to break, but the fiber diameter was as small as possible. Two types of PLDLA-scaffolds forming either a thin 3D structure (2 - 3 fiber thickness) or a thick 3D structure (> 10 fiber thickness) were processed (Fig. 1) which structure thicknesses were estimated from microscopy images. The fiber diameters were analyzed at the end of the study from SEM images. The fiber diameter varied from 800 $\mathrm{nm}$ to $5 \mu \mathrm{m}$.

The PLDLA-scaffolds were pre-incubated for 2 days prior to cell seeding. Because PLDLA is biodegradable material, medium $\mathrm{pH}$ was monitored prior and during cell experiments. The $\mathrm{pH}$ of the media within the PLDLAscaffolds remained relatively constant, ranging from 7.8 to 8.2, which did not differ from control culture (medium + cells). Moreover, any discernible degradation of the fibers was not detected during the 7 days follow up.

PLDLA-scaffolds were inserted into well plates with CellCrown inserts, which maintained the stability of the scaffolds (Fig. 1). After the cells were cultured onto scaffolds, the following analyses were performed without breaking the scaffold/cell structure.

During culturing, cells were observed with a light microscope. Cells attached to the thick 3D scaffold structures as well as to the laminin-coated wells (Fig. 2D, F). In non-coated wells, attachment was poor (Fig. 2C). Attached cells started to migrate and maturate within 3 days in culture.

A Live/Dead assay was used to check the cell viability on thick PLDLA-scaffolds. The cell viability on PLDLAscaffolds was good, although slightly more dead cells were detected on the PLDLA-scaffold compared to laminin (compare Fig. 2A, B). Most importantly, similar to those 

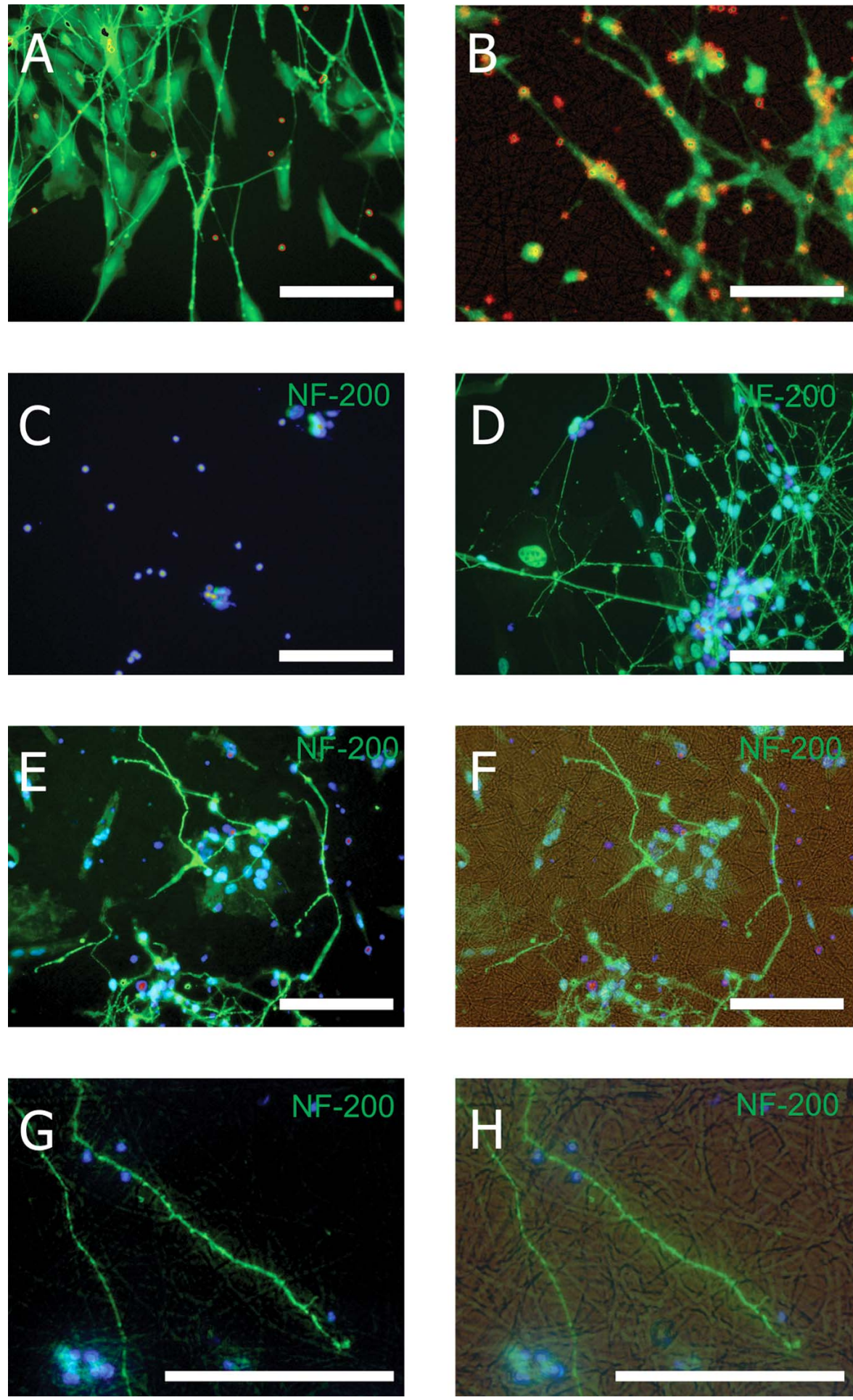

Fig. (2). Neuronal cell growth on thick PLDLA scaffolds. Cells survived well on PLDLA scaffolds (B) compared to laminin-grown cells (A); green labels viable cells and red dead cells. A neuronal characteristic of cells was confirmed by NF-200 staining (green, C-H); Blue: DAPIpositive nuclei. Neurons grew equally well on PLDLA $(\mathbf{E})$ and laminin $(\mathbf{D})$, whereas growth in nontreated wells was very poor $(\mathbf{C})$. Neuronal cells formed neurites that followed PLDLA fibers as shown in the superimposed image (F), and in more detail in G-H. Scale bars: $100 \mu \mathrm{m}$.

cells grown on laminin (Fig. 2D), the morphologic characteristics of the cells on PLDLA fibers were typical for neuronal cells (Fig. 2E for NF-200 staining), whereas neuronal growth in non-treated well plates was very poor (Fig. 2C). Moreover, NF-200 positive neurites seemed to contact the PLA-fibers with tiny filament-like structures (Fig. 2G). Neurites followed the fiber orientation, which was observed as irregular turns in PLDLA fibers (Fig. 2F) compared to the laminin-grown neurites. 

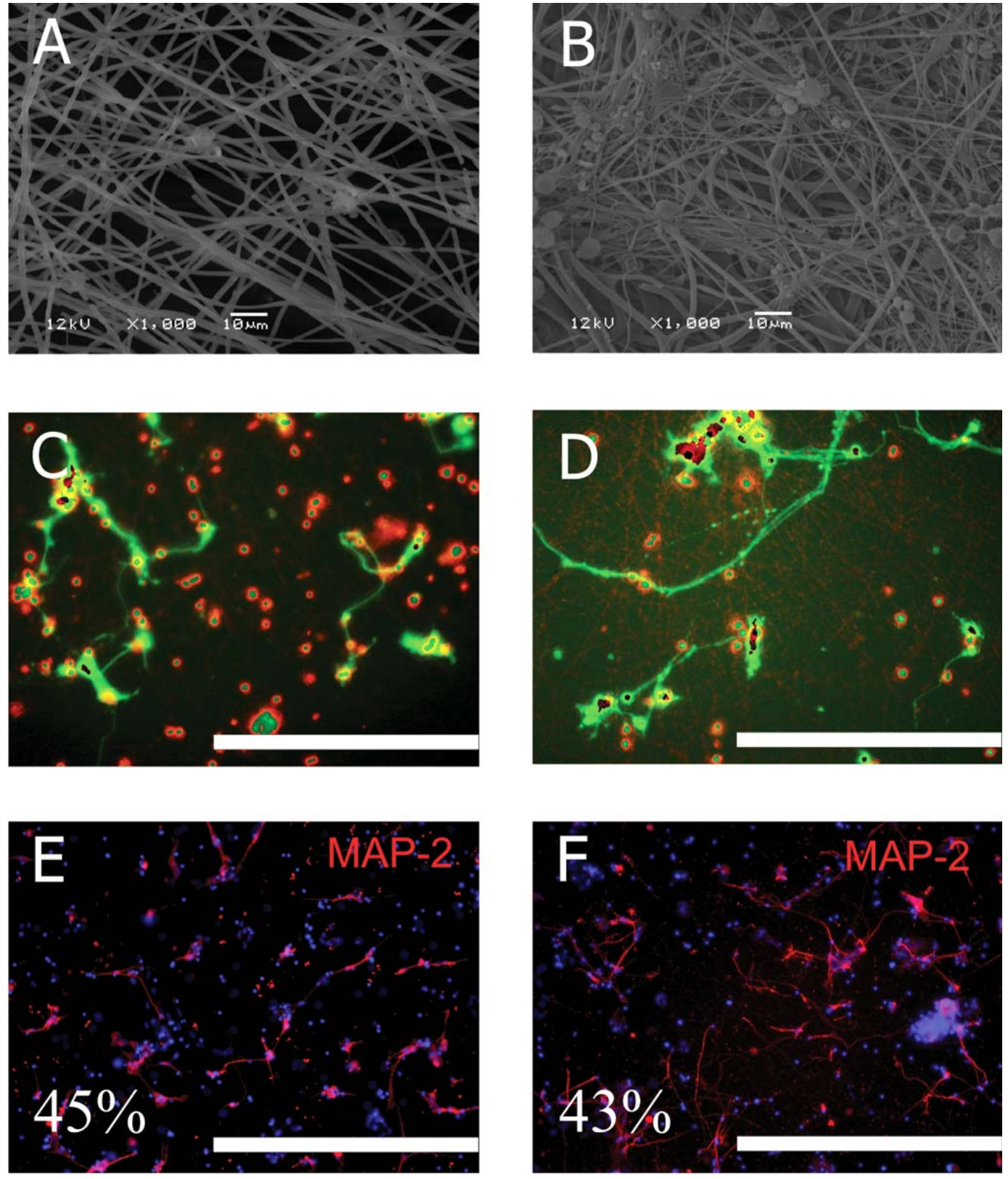

Fig. (3). Neuronal cell growth on thin and thick 3D PLDLA scaffolds. Neuronal cells grew better on thick 3D PLDLA scaffolds than on thin 3D PLDLA scaffolds, as shown in the SEM images (B vs. A), live death analysis (D vs. C), and in MAP-2 staining (F vs. E). Scale bars: (AB) $10 \mu \mathrm{m},(\mathbf{C}-\mathbf{F}) 200 \mu \mathrm{m}$.

\section{Comparison of Thin and Thick 3D Scaffold Structures}

The thin 3D structure comprised an approximately 3fiber thick structure (Fig. 3A) whereas the thick 3D structure comprised an approximately 10-fiber thick structure (Fig. 3B). The amount of MAP-2 positive neuronal cells was similar among the laminin-coated controls, thin 3D structure, and thick 3D structure (36\% vs. $45 \%$ vs. $43 \%$, respectively; compare Fig. 5A to Fig. 3E, F). The total neurite length/cell (median: $116.0 \mu \mathrm{m} v s .111 .5 \mu \mathrm{m} v s .126 .9 \mu \mathrm{m}$ ) was also similar ( $p>0.05$, Kruskall-Wallis) among neurons grown on the laminin, thin 3D structure, or the thick 3D structure, respectively. Average neurite lengths were also similar (median: $58 \mu \mathrm{m} v s .55 .7 \mu \mathrm{m} v s .62 .8 \mu \mathrm{m}, \mathrm{p}>0.05$, Kruskall-
Wallis) between groups. Attachment of the cells, however, was better on the thick 3D structure than on the thin 3D structure (Fig. 3A vs. B) and therefore we focus on the thick 3D structure on the following analysis.

\section{Thick 3D PLDLA Structure}

Representative neuronal growth on the thick 3D PLDLA scaffolds is shown in Fig. (4). An SEM image of the typical morphology of bipolar neurons grown on the thick 3D PLDLA scaffold is shown in Fig. (4E). Moreover, cells grew on fibers and they maturated as neurites outgrew along the fibers, and the neuronal cells formed networks (Fig. 4). The 

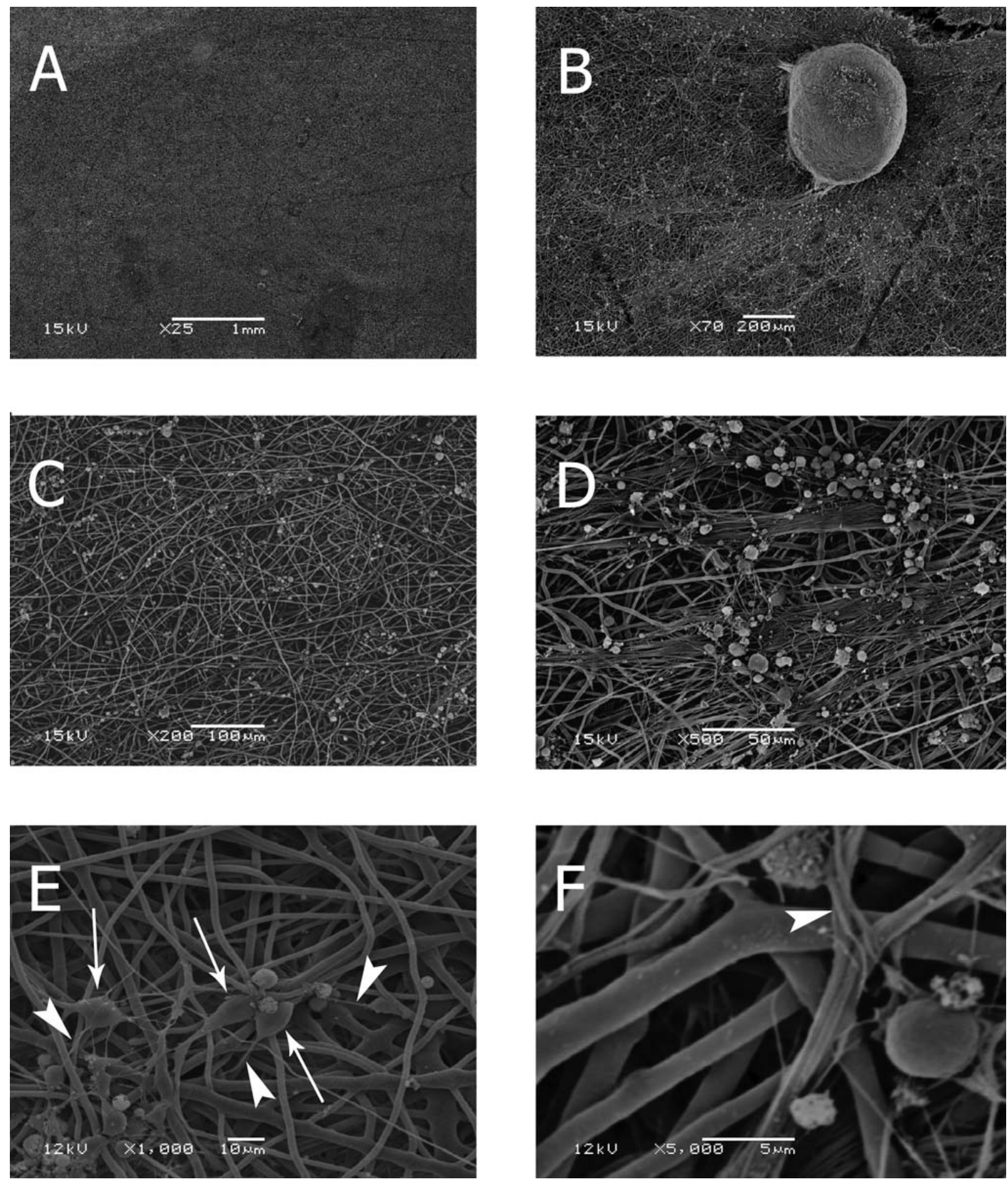

Fig. (4). Representative SEM images of neurons grown on thick 3D PLDLA scaffolds. Neurons grew well on PLDLA scaffolds (A-C), formed networks (D) and neurite outgrowth at least partially followed the fiber alignment (E-F). Scale bars: (A) $1 \mathrm{~mm},(\mathbf{B}) 200 \mu \mathrm{m},(\mathbf{C}) 100$ $\mu \mathrm{m}$, (D) $50 \mu \mathrm{m},(\mathbf{E}) 10 \mu \mathrm{m},(\mathbf{F}) 5 \mu \mathrm{m}$

neuronal cells migrated from the attached neural cell clusters as shown in Fig. (4B).
The thick 3D structure was then functionalized with 10 , 5,1 , or $0.1 \mu \mathrm{g} / \mathrm{ml}$ laminin and neuronal cell growth was analyzed. FITC-labeling showed that laminin incorporated 

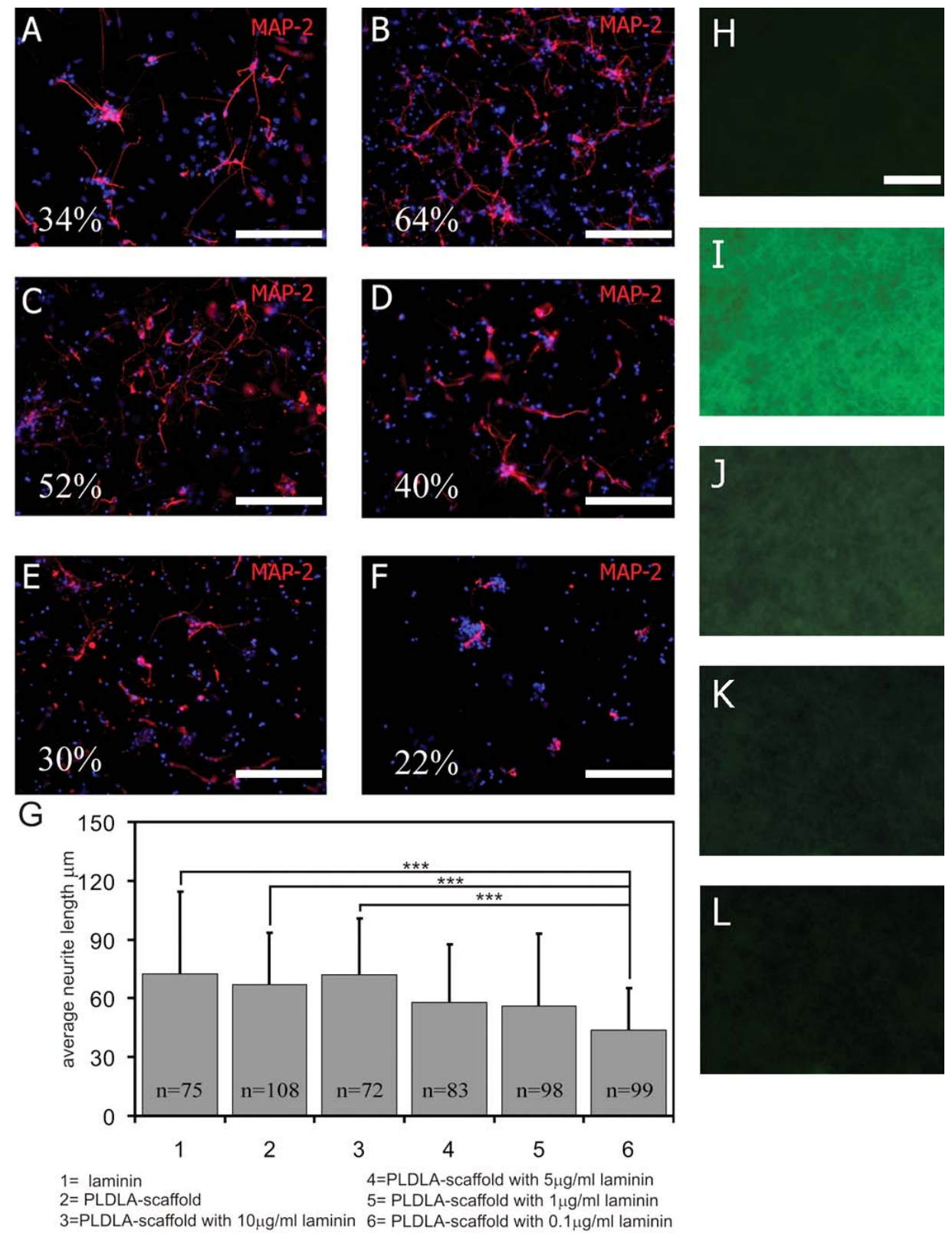

Fig. (5). Functionalization of PLDLA scaffolds. MAP-2 positive neurons (red) grew equally well on laminin (A) and PLDLA scaffolds treated with $10 \mu \mathrm{g} / \mathrm{ml}$ laminin (B). Reduction of laminin to $5 \mu \mathrm{g} / \mathrm{ml}(\mathbf{C}), 1 \mu \mathrm{g} / \mathrm{ml}(\mathbf{D})$, and $0.1 \mu \mathrm{g} / \mathrm{ml}(\mathbf{E})$ resulted in poorer neuronal cell growth. Neuronal growth in nontreated polystyrene wells was very poor $(\mathbf{F})$. Average neurite length in laminin, PLDLA, or PLDLA +10 $\mu \mathrm{g} / \mathrm{ml}$ laminin was similar, but neurons grown on PLDLA $+0.1 \mu \mathrm{g} / \mathrm{ml}$ formed significantly shorter neurites $(\mathbf{G})$. The attachment of laminin to PLDLA fibers were evaluated with FITC-labeling. Labeled fibers is presented in figures $\mathrm{H}-\mathrm{L}$ : $\mathrm{H}=\mathrm{without}$ laminin, $\mathrm{I}=10 \mu \mathrm{g} / \mathrm{ml}, \mathrm{J}=5$ $\mu \mathrm{g} / \mathrm{ml}, \mathrm{K}=1 \mu \mathrm{g} / \mathrm{ml}$, and $\mathrm{L}=0.1 \mu \mathrm{g} / \mathrm{ml}$. Scale bars: from A to $\mathrm{F}: 100 \mu \mathrm{m}$, from $\mathrm{H}$ to $\mathrm{L}: 50 \mu \mathrm{m} . \mathrm{n}=$ amount of MAP-2 positive cells counted, errors bars present standard deviation, ${ }^{* * *} \mathrm{p}<0.001$ Mann-Whitney U-test.

onto fibers (Fig. 5H-L) and intensity of the labeling correlated with the laminin concentration used. Cell viability and the amount of MAP-2 positive cells were similar to that of cells on the nonfunctionalized thick 3D structures in scaffolds functionalized with 10 or $5 \mu \mathrm{g} / \mathrm{ml}$ of laminin (see Fig. 5). Of all the functionalized scaffolds, cell viability and neuronal phenotype was lowest in thick 3D structures treated with $0.1 \mu \mathrm{m} / \mathrm{ml}$ laminin (Fig. 5E). The neurite lengths are presented in Fig. (5G). The mean neurite amount/cell was 2. Neurite outgrowth on the laminin-treated thick 3D structures differed significantly from that on nonfunctionalized scaffolds $(\mathrm{p}<0.000$, Kruskall-Wallis). The thick 3D scaffolds not treated with laminin and those treated with 10 $\mu \mathrm{m} / \mathrm{ml}$ laminin supported neurite outgrowth well and both the total neurite length and average neurite length were similar among cells grown on these matrices $(p>0.05)$. Both the total neurite length and mean length gradually decreased when the concentration of the laminin coating was decreased (see Fig. 5G for details). 


\section{DISCUSSION}

The results of the present study demonstrated that an unorganized 3D nanofibrous PLDLA scaffold is a promising growth matrix for hESC-derived neurons. The cells were able to attach, grow, differentiate, and migrate on PLDLA scaffolds as well as on their normal culture matrix, that is, laminin-coated polystyrene well plates.

Our results indicated that the electrospun 3D PLDLA scaffolds are suitable for culturing hESC-derived neuronal cells. These observations are consistent with earlier studies in which the biocompatibility of polylactide-scaffolds and neuronal cells was examined $[10,20]$. The normal extracellular cell matrix is a complex 3D biopolymer structure that surrounds cells in tissue. By mimicking that structure, it is possible to create a structure that enhances cell survival, proliferation, and maturation [21]. The process of electrospinning produces a highly porous structure containing very thin, even less than $70 \mathrm{~nm}$ diameter, fibers [15]. This type of structure mimics the extracellular matrix and is therefore suitable material for scaffolds, as demonstrated here. The pores initiate the cell growth while the fibres provide the structure for the system. A wide range of different synthetic polymers can be processed via electrospinning [9]. PLDLA fibers with a diameter ranging from $800 \mathrm{~nm}$ to $5 \mu \mathrm{m}$ support neuronal cell growth, although the thinner fibers are better for orienting neurite growth, as reported previously [14].

Unlike most previous studies, we used a co-polymer of L-lactide and D-lactide that is slowly biodegradable [22] [23]. The mix of $4 \%$ D-lactide and $96 \%$ L-lactide copolymer has better degradation properties in the body than PLLA, which does not necessarily fully degrade or at least degrades very slowly in a biologic environment [22]. Yang and colleagues (2005) followed the growth of neonatal mouse neurons on PLLA scaffolds for 2 days [10]. Here, we extended the follow-up period to 1 week and the results showed that neuronal cells grew well on PLDLA scaffolds after a longer culturing period. At the end of this follow-up time, biodegradation of the material was not observed which is in line with previous study reporting only minor degradation of PLDLA fibers during first 5 weeks in vitro conditions [23]. In addition, the $\mathrm{pH}$ of the culturing media was monitored during the culturing and remained constant during the follow-up. Based on these findings, PLDLA is a suitable scaffold material for neuronal cells. Whether neuronal cells grown on PLDLA scaffold form functional networks as shown for laminin grown neurons [24] will be addressed in the future studies.

The cells grew well on the randomly-oriented PLDLA scaffolds. Both aligned and randomly-oriented fibers have been examined in previous studies. The results of these studies suggest that, compared to randomly-oriented fibers, aligned fibers form a better scaffold for neuronal cells due to better neurite outgrowth $[14,25]$. In the present study, however, the neurites grew equally well on randomlyoriented fibers and in laminin-coated control wells, the surface of which are known to support neurite outgrowth [18]. Randomly orientated fibers seemed to guide neurite growth (neurites grew along the fibers) to some extent. Processed fibers can be modified by functionalizing them with different substrates to increase cell attachment and maturation [12, 26-28]. Previously, Chiu and colleagues (2007) evaluated the functionalization of nanofibrous polyL-lactide with collagen for supporting osteoblast growth whereas Koh and colleagues (2008) reported nanofibrous poly-L-lactide with laminin for supporting PC12 neurite growth. Here, we functionalized PLDLA fibers by laminin treatment which was verified by FITC-labeling. Unexpectedly, coating the PLDLA fibers with laminin did not increase neurite outgrowth, which further suggests that the randomly-orientated PLDLA scaffolds supports neurite outgrowth as well as laminin alone. In previous study, functionalization of PLLA with laminin using various techniques showed that electrospun blended lamininpolymer nanofibers supported $\mathrm{PC} 12$ cells growth better that PLLA by itself but still the poly-L-lysine treated cell culture wells were superior [29]. The functionalization of PLDLA with laminin seemed to support the maintenance of MAP-2 positive neurons in higher concentrations $(10$ or $5 \mu \mathrm{g} / \mathrm{ml})$ whereas the lower concentrations ( 1 to $0.1 \mu \mathrm{g} / \mathrm{ml}$ ) resulted in poorer maintenance. This suggests that laminin used for functionalization works at similar concentrations as used for normal cell culture well coatings and thus no clear positive effect (better growth of the cells or reduced use of laminin) is gained by the functionalization. As the FITC labeling showed that the $10 \mu \mathrm{g} / \mathrm{ml}$ of laminin incorporates very smoothly on PLDLA scaffolds and supports the neuronal cell growth, it may suggest that incorporation of less amount of laminin disrupts the nano-topography of PLDLA and therefore results in poorer neuronal cell attachment and neurite outgrowth. Thus, as PLDLA as such seems to work well without any further modifications, there is no need to add expensive human laminin which makes processing of the scaffold also less complicated.

The results of the present study indicate that hESCderived neurons grow and mature well on 3D PLDLA scaffolds, and the functionalization fibers with laminin do not bring any extra value. These findings suggest that a more controlled and transplantable scaffolds can be processed for human-derived neurons which opens new avenues for in vitro studies of neuronal network functionality and the development of tissue-engineered products for clinical purposes.

\section{ACKNOWLEDGEMENTS}

We would like to thank the personnel of Regea for support of human embryonic stem cell research. The original hESC lines were kindly provided by Prof. Outi Hovatta, Karolinska Institute, Sweden. We wish to thank also to Dr. Jarno M. A. Tanskanen for photography assistance. This work was supported by The Academy of Finland; Competitive Research Funding of Pirkanmaa Hospital District, Finland; and the Employment and Economic Development Center for Pirkanmaa, Finland.

\section{REFERENCES}

[1] Levenberg S, Huang NF, Lavik E, Rogers AB, Itskovitz-Eldor J, Langer R. Differentiation of human embryonic stem cells on threedimensional polymer scaffolds. Proc Natl Acad Sci USA 2003; 100: 12741-6. 
[2] Lindvall O, Kokaia Z, Martinez-Serrano A. Stem cell therapy for human neurodegenerative disorders-how to make it work. Nat Med 2004; 10 (Suppl): S42-50.

[3] Vasita R, Katti DS. Nanofibers and their applications in tissue engineering. Int J Nanomed 2006; 1: 15-30.

[4] Teixeira AI, Duckworth JK, Hermanson O. Getting the right stuff: controlling neural stem cell state and fate in vivo and in vitro with biomaterials. Cell Res 2007; 17: 56-61.

[5] Li W, Guo Y, Wang H, et al. Electrospun nanofibers immobilized with collagen for neural stem cells culture. J Mater Sci Mater Med 2008; 19: 847-54.

[6] Novikov LN, Novikova LN, Mosahebi A, Wiberg M, Terenghi G, Kellerth JO. A novel biodegradable implant for neuronal rescue and regeneration after spinal cord injury. Biomaterials 2002; 23: 3369-76.

[7] Schnell E, Klinkhammer K, Balzer S, et al. Guidance of glial cell migration and axonal growth on electrospun nanofibers of polyepsilon-caprolactone and a collagen/poly-epsilon-caprolactone blend. Biomaterials 2007; 28: 3012-25.

[8] Shin H, Jo S, Mikos AG. Biomimetic materials for tissue engineering. Biomaterials 2003; 24: 4353-64.

[9] Subbiah T, Bhat GS, Tock RW, Parameswaran S, Ramkumar SS. Electrospinning of Nanofibers. J Appl Polym Sci 2005; 96: 557-69.

[10] Yang F, Murugan R, Wang S, Ramakrishna S. Electrospinning of nano/micro scale poly(L-lactic acid) aligned fibers and their potential in neural tissue engineering. Biomaterials 2005; 26: 260310.

[11] Wen X, Tresco PA. Effect of filament diameter and extracellular matrix molecule precoating on neurite outgrowth and Schwann cell behavior on multifilament entubulation bridging device in vitro. $\mathbf{J}$ Biomed Mater Res A 2006; 76: 626-37.

[12] Nakaji-Hirabayashi T, Kato K, Iwata H. Hyaluronic acid hydrogel loaded with genetically-engineered brain-derived neurotrophic factor as a neural cell carrier. Biomaterials 2009; 30: 4581-9.

[13] Ashammakhi N, Ndreu A, Piras AM, et al. Biodegradable nanomats produced by electrospinning: expanding multifunctionality and potential for tissue engineering. J Nanosci Nanotechnol 2007; 7: 862-82.

[14] Yang F, Xu CY, Kotaki M, Wang S, Ramakrishna S. Characterization of neural stem cells on electrospun poly(L-lactic acid) nanofibrous scaffold. J Biomater Sci Polym Ed 2004; 15: 1483-97.

[15] Nikkola L, Seppala J, Harlin A, Ndreu A, Ashammakhi N. Electrospun multifunctional diclofenac sodium releasing nanoscaffold. J Nanosci Nanotechnol 2006; 6: 3290-5.

[16] Ella V, Kellomaki M, Tormala P. In vitro properties of PLLA screws and novel bioabsorbable implant with elastic nucleus to replace intervertebral disc. J Mater Sci Mater Med 2005; 16: 65562.
[17] Rajala K, Hakala H, Panula S, et al. Testing of nine different xenofree culture media for human embryonic stem cell cultures. Hum Reprod (Oxford, England) 2007; 22: 1231-8.

[18] Nat R, Nilbratt M, Narkilahti S, Winblad B, Hovatta O, Nordberg A. Neurogenic neuroepithelial and radial glial cells generated from six human embryonic stem cell lines in serum-free suspension and adherent cultures. Glia 2007; 55: 385-99.

[19] Sundberg M, Jansson L, Ketolainen J, et al. CD marker expression profiles of human embryonic stem cells and their neural derivatives, determined using flow-cytometric analysis, reveal a novel CD marker for exclusion of pluripotent stem cells. Stem Cell Res 2009; 2: 113-24.

[20] Corey JM, Gertz CC, Wang BS, et al. The design of electrospun PLLA nanofiber scaffolds compatible with serum-free growth of primary motor and sensory neurons. Acta Biomater 2008; 4: 86375.

[21] Srouji S, Kizhner T, Suss-Tobi E, Livne E, Zussman E. 3-D Nanofibrous electrospun multilayered construct is an alternative ECM mimicking scaffold. J Mater Sci Mater Med 2008; 19: 124955.

[22] Kim K, Yu M, Zong X, et al. Control of degradation rate and hydrophilicity in electrospun non-woven poly(D,L-lactide) nanofiber scaffolds for biomedical applications. Biomaterials 2003; 24: 4977-85.

[23] Ella V, Gomes ME, Reis RL, Tormala P, Kellomaki M. Studies of P(L/D)LA 96/4 non-woven scaffolds and fibres; properties, wettability and cell spreading before and after intrusive treatment methods. J Mater Sci Mater Med 2007; 18: 1253-61.

[24] Heikkila TJ, Yla-Outinen L, Tanskanen JM, et al. Human embryonic stem cell-derived neuronal cells form spontaneously active neuronal networks in vitro. Exp Neurol 2009; 218: 109-16.

[25] Corey JM, Lin DY, Mycek KB, et al. Aligned electrospun nanofibers specify the direction of dorsal root ganglia neurite growth. J Biomed Mater Res A 2007; 83: 636-45.

[26] Gupta D, Venugopal J, Prabhakaran MP, et al. Aligned and random nanofibrous substrate for the in vitro culture of Schwann cells for neural tissue engineering. Acta Biomater 2009; 5: 2560-9.

[27] Chiu JB, Liu C, Hsiao BS, Chu B, Hadjiargyrou M. Functionalization of poly(L-lactide) nanofibrous scaffolds with bioactive collagen molecules. J Biomed Mater Res A 2007; 83: 1117-27.

[28] Auer S, Lappalainen RS, Skottman H, Suuronen R, Narkilahti S, Vikholm-Lundin I. An antibody surface for selective neuronal cell attachment. J Neurosci Methods 2009; 186: 72-6.

[29] Koh HS, Yong T, Chan CK, Ramakrishna S. Enhancement of neurite outgrowth using nano-structured scaffolds coupled with laminin. Biomaterials 2008; 29: 3574-82.

\section{(C) Ylä-Outinen et al.; Licensee Bentham Open.}

This is an open access article licensed under the terms of the Creative Commons Attribution Non-Commercial License (http://creativecommons.org/ licenses/by-nc/3.0/), which permits unrestricted, non-commercial use, distribution and reproduction in any medium, provided the work is properly cited. 